\title{
Our thanks to the editors-in-chief: Ulrich Förstner (Sediments) and Wim Salomons (Intercompartment)
}

\author{
Zhihong Xu • Philip N. Owens
}

Received: 13 October 2010 /Accepted: 13 October 2010/Published online: 26 October 2010

(C) Springer-Verlag 2010

The year 2010 marks the tenth anniversary of the Journal of Soils and Sediments (JSS). Many would say this marks an important milestone in the life of the journal: a sign that the journal has successfully found a niche within the evergrowing number of academic journals. Not only has the journal survived its first 10 years, but there are many signs that the future is looking very good for the journal. In the first few years, about 40 papers were published in four issues each year, whereas in 2010 there are eight issues and about 360 manuscripts have been received. Due to the increasing number of submitted good manuscripts, the publisher has agreed to increase the frequency of the journal. Both the number and the quality of the submitted manuscripts show the growing acceptance of the journal. In the early days of the journal, the authorship of manuscripts was a close community, which often led to self-citations in the manuscripts. This has been rectified with the expansion of the number of submitted manuscripts and strong editing rules. As a result, the Journal Impact Factor for the past 2 years has been around 2.7, quite an achievement for a young journal. We would like to thank Ulrich Förstner and Wim Salomons for these achievements. In two editorials, they look back at the history of sediment pollution research. The "short" editorial provides an overview of the past 60 years, and the broad developments from academic geochemical research to interdisciplinary research, and the required interfacing of natural and social sciences for the management of sediments. The "long" editorial is a detailed assessment of the past 10 years, highlighting key areas of sediment research and the role of the JSS.

From 2011, Zhihong $\mathrm{Xu}$ will continue to serve as the editor-in-chief (Soils) while Phil Owens will be the editor-inchief (Sediments) for the JSS. In an editorial, which will appear in the first issue of 2011, we will give you an overview of how we intend to further expand the journal and make it even more attractive to the sediment and soil community.

\section{Z. Xu $(\bowtie)$}

Griffith University, Environmental Futures Centre

and School of Biomolecular and Physical Sciences,

170 Kessels Road,

Nathan QLD 4111, Australia

e-mail: zhihong.xu@griffith.edu.au

P. N. Owens $(\square)$

University of Northern British Columbia,

Environmental Science Program,

3333 University Way,

Prince George, BC V2N 4Z9, Canada

e-mail: owensp@unbc.ca 